\title{
The neuroendocrine sequelae of paediatric craniopharyngioma: a 40-year meta-data analysis of 185 cases from three UK centres
}

\author{
Timothy Shao Ern Tan 1,2, Leena Patel1,2, Jaya Sujatha Gopal-Kothandapani', \\ Sarah Ehtisham ${ }^{1}$, Esieza Clare Ikazoboh ${ }^{3}$, Richard Hayward ${ }^{3}$, Kristian Aquilina ${ }^{3}$, \\ Mars Skae', Nicky Thorp4 , Barry Pizer4, Mohammed Didi ${ }^{4}$, Conor Mallucci ${ }^{4}$, \\ Joanne C Blair4, Mark N Gaze ${ }^{3,5}$, Ian Kamaly-AsI ${ }^{1}$, Helen Spoudeas ${ }^{3,5}$ and \\ Peter E Clayton ${ }^{1,2}$
}

${ }^{1}$ Royal Manchester Children's Hospital, Manchester, UK, ${ }^{2}$ The School of Medical Sciences, Faculty of Biology, Medicine and Health, University of Manchester, Manchester, UK, ${ }^{3}$ Great Ormond Street Hospital for Children NHS Foundation Trust, London, UK, ${ }^{4}$ Alder Hey Children's NHS Foundation Trust, Liverpool, UK, and ${ }^{5}$ University College London Hospitals NHS Foundation Trust, London, UK

\author{
Correspondence \\ should be addressed \\ to T S E Tan \\ Email \\ timothy.tan.shao.ern@ \\ doctors.org.uk
}

\begin{abstract}
Objectives: The management of paediatric craniopharyngiomas was traditionally complete resection (CR), with better reported tumour control compared to that by partial resection (PR) or limited surgery (LS). The subsequent shift towards hypothalamic sparing, conservative surgery with adjuvant radiotherapy (RT) to any residual tumour aimed at reducing neuroendocrine morbidity, has not been systematically studied. Hence, we reviewed the sequelae of differing management strategies in paediatric craniopharyngioma across three UK tertiary centres over four decades. Methods: Meta-data was retrospectively reviewed over two periods before (1973-2000 (Group A: $n=100)$ ) and after (1998-2011 (Group B: $n=85)$ ) the introduction of the conservative strategy at each centre.

Results: Patients had CR (A: $34 \%$ and B: 19\%), PR (A: $48 \%$ and B: $46 \%$ ) or LS (A: $16 \%$ and B: $34 \%$ ), with trends reflecting the change in surgical approach over time. Overall recurrence rates between the two periods did not change ( $A$ : $38 \%$ vs $B: 32 \%$ ). More patients received RT in B than A, but recurrence rates were similar: for $A, 28 \%$ patients received RT with 9 recurrences (32\%); for B, 62\% received RT with 14 recurrences $(26 \%)$. However, rates of diabetes insipidus $(P=0.04)$, gonadotrophin deficiency $(P<0.001)$ and panhypopituitarism $(P=0.001)$ were lower in B than those in A. In contrast, post-operative obesity (BMI SDS $>+2.0)(P=0.4)$ and hypothalamic $(P=0.1)$ and visual $(P=0.3)$ morbidity rates were unchanged.

Conclusion: The shift towards more conservative surgery has reduced the prevalence of hormone deficiencies, including diabetes insipidus, which can be life threatening. However, it has not been associated with reduced hypothalamic and visual morbidities, which remain a significant challenge. More effective targeted therapies are necessary to improve outcomes.
\end{abstract}

\section{Introduction}

Craniopharyngiomas are rare neuroectodermal tumours that make up $5-13 \%$ of paediatric and $1-4 \%$ of adult brain tumours $(1,2)$. The overall incidence is estimated to be 0.13 new cases per 100000 people/year with a
() 2017 European Society of Endocrinology Printed in Great Britain bimodal age distribution, peaking at ages $5-14$ years and 65-74 years (3).

Whether suprasellar and/or intrasellar, they are in close proximity to vital structures including the 
optic nerves and chiasm, pituitary stalk and gland, hypothalamus, third ventricle and internal carotid artery. Thus, although classed as a benign tumour that does not metastasise, craniopharyngiomas can be difficult to resect and control owing to their location as well as size, local extension, adherence and unpredictable propensity to recur regardless of the initial treatment modality (1). Local invasion of the tumour as well as its treatment with surgery and radiotherapy (RT) can compromise structures in close proximity to the tumour, and as a result its their impact on survival, morbidity and quality of life can be devastating $(4,5,6,7,8,9)$.

Radical excision and conservative subtotal resection are the two dominant surgical strategies. Radical surgery with complete resection (CR) aims to achieve long-term cure and was a favoured treatment for many years (10). The drawback of this aggressive strategy is injury to vital tissues, which results in a high frequency of visual impairment, hypothalamic dysfunction (11), central diabetes insipidus (DI) (4) and anterior pituitary hormone deficiencies (12), without proven reduction in relapse and progression rates.

Hypothalamic sparing partial resection (PR) allows decompression and may reduce the subsequent adjuvant RT target volume. The aim is to avoid further morbidity and prevent early progression of the residual tumour (13). This has been reported to have equivalent tumour control rates as CR.

Since 2000, there has been a gradual change in surgical practice towards tailored individual riskbased interventions, more conservative surgery and early or delayed (at recurrence) RT to achieve disease control (14, 15). The United Kingdom Children's Cancer Study Group (UKCCSG) and British Society for Paediatric Endocrinology and Diabetes (BSPED) published the first consensus management guidelines (UKMG) (16). This has formed the basis of UK practice since 2005. However, in the absence of randomised trials for this rare disease, the optimal strategy to achieve disease control with minimal morbidity remains elusive. In this current study, we aim to review the neuroendocrine outcomes resulting from the change in primary management recommended by the 2005 UKMG (16) of newly diagnosed paediatric craniopharyngiomas from three of the UK's largest national tertiary centres over four decades from 1973 to 2011. Management of recurrences is not within the remit of this study.

\section{Subjects and methods}

\section{Patient cohorts and time periods}

Six independent audits that reviewed data from 1973 to 2011 were undertaken at three tertiary centres in the UK to evaluate the management of children with craniopharyngioma (16). Since 2010, the three centres Royal Manchester Children's Hospital (RMCH), Great Ormond Street Children's Hospital (GOSH) and Alder Hey Children's Hospital (AHCH) have participated in a national hypothalamic-pituitary axis tumour (HPAT) multiprofessional discussion forum to share decision making and improve care (17). Meta-data from these six audits were obtained and retrospectively analysed (Table 1). To compare outcomes before and after the change in surgical strategy at each centre, we merged the GOSH Study 1 (18) and RMCH Study 1 to form Group A (1973-2000), and GOSH Study 2, RMCH Studies 2 and 3 and the AHCH study (19) to form Group B (1998-2011).

Each study period included only children with newly diagnosed craniopharyngioma managed at the tertiary centre by a multispeciality team including paediatric endocrinologists, clinical oncologists, neurosurgeons, neuroradiologists and ophthalmologists. The median duration of follow-up across the three centres was 3.7 $(0.25-19.2)$ years.

\section{Management for primary tumour}

For Group A patients, the surgical strategy aimed to achieve CR where possible. For Group B patients, including those who were diagnosed before 2005, risk was assessed according to the 2005 UKMG: good risk factors included small tumour $(<2-4 \mathrm{~cm})$, no hydrocephalus, no hypothalamic syndrome or breach of 3rd ventricle, whereas poor risk factors included larger (retrochiasmatic) tumour $(>2-4 \mathrm{~cm})$, hydrocephalus and hypothalamic syndrome with or without breach of the 3rd ventricle based on our experience of grading hypothalamic morbidity $(16,18)$. CR was recommended for patients stratified into 'good' risk, whereas conservative surgery with the addition of immediate or delayed RT (according to age cut-off at 5 years) was recommended for the 'poor' risk group. RT after CR was not recommended unless there was evidence of post-operative tumour recurrence. Emphasis was placed on minimising hypothalamic morbidity through a more tailored conservative approach. For tumours 
Table 1 Patient characteristics from 6 studies undertaken at 3 UK tertiary centres from 1973 to 2011, subdivided into two study groups: Group A including 2 studies from 2 centres over 1973-2000 and Group B including 4 studies from 3 centres over 1998-2011.

\begin{tabular}{|c|c|c|c|c|c|c|}
\hline \multirow[b]{2}{*}{ Studies } & \multicolumn{2}{|c|}{ Group A: 1973-2000 $(n=100)$} & \multicolumn{4}{|c|}{ Group B: 1998-2011 $(n=85)$} \\
\hline & GOSH Study 1 & RMCH Study 1 & GOSH Study 2 & RMCH Study 2 & RMCH Study 3 & AHCH Study \\
\hline Study period & 1973-1994 & 1978-2000 & 1998-2010 & 2000-2004 & 2005-2010 & 2005-2011 \\
\hline No. of patients & 75 & 25 & 40 & 12 & 13 & 20 \\
\hline Gender & $\begin{array}{l}\text { Male: } 42 \\
\text { Female: } 33\end{array}$ & $\begin{array}{l}\text { Male: } 17 \\
\text { Female: } 8\end{array}$ & $\begin{array}{l}\text { Male: } 18 \\
\text { Female: } 22\end{array}$ & $\begin{array}{l}\text { Male: } 6 \\
\text { Female: } 6\end{array}$ & $\begin{array}{l}\text { Male: } 7 \\
\text { Female: } 6\end{array}$ & $\begin{array}{l}\text { Male: } 10 \\
\text { Female: } 10\end{array}$ \\
\hline $\begin{array}{l}\text { Mean duration of } \\
\text { follow up (years) } \\
\text { (range) }\end{array}$ & $6.40(1.50-19.20)$ & 8.20 (NA) & $5.99(4.81-7.16)$ & $2.61(0.22-6.13)$ & $3.69(1.14-7.1)$ & $3.00(0.25-6.0)$ \\
\hline \multirow[t]{2}{*}{$\begin{array}{l}\text { Mean tumour } \\
\text { height in midline } \\
(\mathrm{cm}) \text { (range) }\end{array}$} & $\begin{array}{c}\geq 3.5 \text { in } 26 / 51 \\
(51 \%),<3.5 \text { in } \\
25 / 49(49 \%)\end{array}$ & NA & NA & $\begin{array}{c}3.57(1.8-5), \geq 2 \\
\text { in } 8 / 12(67 \%) \\
<2 \text { in } 1 / 12(8 \%)\end{array}$ & $\begin{array}{l}4.63(2.0-9.5) \\
\geq 2 \text { in } 12 / 13 \\
(92 \%)\end{array}$ & $\begin{array}{l}2-4 \text { in } 18 / 20(90 \%) \\
<2 \text { in } 2 / 20(10 \%)\end{array}$ \\
\hline & $\begin{array}{l}\text { Median tumour } \\
\text { volume: } \\
41.0 \mathrm{~mL} \\
(1.4-471.0 \mathrm{~mL})\end{array}$ & & & $\begin{array}{l}\text { Size not known: } \\
3 / 12(25 \%)\end{array}$ & $\begin{array}{l}\text { Size not known: } \\
1 / 13(8 \%)\end{array}$ & \\
\hline $\begin{array}{l}\text { Mean age at } \\
\text { diagnosis (years) } \\
\text { (range) }\end{array}$ & $6.60(1.00-16.40)$ & 7.70 (NA) & $8.60(7.23-9.99)$ & $9.01(3.83-16.00)$ & $\begin{array}{l}10.6(3.50- \\
16.20)\end{array}$ & $10.80(1.50-15.50)$ \\
\hline $\begin{array}{l}\text { Mean height SDS at } \\
\text { diagnosis (range) }\end{array}$ & NA & $\begin{array}{l}-1.07(-3.70 \text { to } \\
+1.40)\end{array}$ & NA & $\begin{array}{l}-2.13(-5.25 \text { to } \\
+0.99)\end{array}$ & $\begin{array}{l}-1.28(-3.28 \text { to } \\
+0.14)\end{array}$ & $\begin{array}{l}-0.90(-2.44 \text { to } \\
0.68)\end{array}$ \\
\hline $\begin{array}{l}\text { Mean height SDS at } \\
\text { follow-up (range) }\end{array}$ & NA & $\begin{array}{l}-0.48(-3.90 \text { to } \\
+1.50)\end{array}$ & NA & $\begin{array}{l}-0.96(-4.76 \text { to } \\
+2.25)\end{array}$ & $\begin{array}{l}-0.50(-2.33 \text { to } \\
+1.45)\end{array}$ & $\begin{array}{l}-0.70(-2.13 \text { to } \\
0.65)\end{array}$ \\
\hline $\begin{array}{l}\text { Mean BMI SDS at } \\
\text { diagnosis (range) }\end{array}$ & NA & $\begin{array}{l}+0.86(-2 \text { to } \\
+2.5)\end{array}$ & $\begin{array}{l}+0.88(-2.23 \text { to } \\
+4.52)\end{array}$ & $\begin{array}{l}+0.29(-1.28 \text { to } \\
+1.54)\end{array}$ & $\begin{array}{l}+0.63(-2.92 \text { to } \\
+2.61)\end{array}$ & $\begin{array}{l}+1.40(-1.92 \text { to } \\
+3.99)\end{array}$ \\
\hline $\begin{array}{l}\text { Mean BMI SDS at } \\
\text { follow-up (range) }\end{array}$ & NA & $\begin{array}{l}+1.39(-2.15 \text { to } \\
+4.3)\end{array}$ & $\begin{array}{l}+2.08(+0.20 \text { to } \\
+4.50)\end{array}$ & $\begin{array}{l}+2.28(+0.26 \text { to } \\
+3.92)\end{array}$ & $\begin{array}{l}+1.56(-0.71 \text { to } \\
3.77)\end{array}$ & $\begin{array}{l}+1.66(-0.58 \text { to } \\
+3.51)\end{array}$ \\
\hline
\end{tabular}

AHCH, Alder Hey Childrens' Hospital; GOSH, Great Ormond Street Hospital; NA, not available; RMCH, Royal Manchester Childrens' Hospital.

with a major cystic component and/or hydrocephalus, patients were re-stratified after endoscopic drainage as the procedure enabled better visualisation of the floor of the third ventricle.

In the $\mathrm{AHCH}$ series (in Group B), the UKMG were combined with the Paris grading method for hypothalamic involvement (19). Here, risk was graded as very high, high, moderate and low based on the presence of hypothalamic syndrome, tumour size $>2 \mathrm{~cm}$, hydrocephalus and breach of floor of the third ventricle. When used for initial management, fractionated external beam radiotherapy, with doses between 50Gy/30\# and $54 \mathrm{~Gy} / 30 \#$, was the standard of care during both study periods.

\section{Pre-operative and post-operative neuroimaging}

All patients had pre- and post-operative neuroimaging with 3-6 monthly follow-up scans depending on treatment era (CT before 1986, MRI subsequently).

Based on the surgical opinion and confirmed by postoperative neuroimaging $(\mathrm{MRI} \pm \mathrm{CT})$, the extent of tumour resection was classified as CR or PR when it was total or subtotal removal respectively. Limited surgery (LS) refers to procedures aimed at cyst drainage and treating tumourrelated hydrocephalus. When comparing outcomes with CR, we have described both PR and LS as incomplete surgery (IS).

Tumour recurrence was defined as evidence on neuroimaging of solid and/or cystic tumour regrowth at any time after surgical resection and/or 3 or more months after RT (to avoid misclassification of RT-induced cysts as recurrences) $(18,19)$.

\section{Pre-operative and post-operative endocrine, hypothalamic and visual function}

Pre- and post-op endocrine function was assessed with standard protocols at each tertiary centre. In addition to clinical features, growth and pubertal status, anterior pituitary function at diagnosis was assessed from baseline biochemical investigations, including insulin-like growth factor-1 (IGF-1), 
prolactin, thyroid-stimulating hormone (TSH) and free thyroxine, gonadotrophins, 08:00-09:00 h adrenocorticotrophic hormone (ACTH) and cortisol, before any dexamethasone. Dynamic tests of growth hormone $(\mathrm{GH})$, cortisol reserve and gonadotrophin levels were performed before surgery when possible, and in all patients during follow-up. Posterior pituitary function and adequacy of anti-diuretic hormone (ADH) secretion was assessed from fluid input/output, paired early morning plasma and urine electrolytes and osmolality, and, if required, a water deprivation. Our endocrine outcomes were assessed by the prevalence rates of endocrine replacement therapy and obesity defined as a BMI SDS $>+2(19,20)$. For all patients, the same UK population reference standard was used to calculate BMI SDS (21).

Hypothalamic morbidity was assessed from the following parameters: the absence or presence of hyperphagia, sleep-wake disturbance, impaired temperature regulation, impaired thirst, weight gain and change in affective behaviour or memory. Visual acuity and visual fields were assessed by experienced ophthalmologists. Children unable to cooperate with the assessment of visual acuity were given a score based on visual evoked potentials.

\section{Statistical analysis}

Analyses were performed with the Statistical Package for the Social Sciences, version 22 (SPSS by IBM). Differences between categorical and continuous variables were analysed by Pearson's chi-squared test and analysis of variance.

\section{Results}

\section{Clinical characteristics of patients}

Between 1973 and 2011, 185 (100 male, 85 female) patients with craniopharyngioma were recruited from GOSH $(n=115), \mathrm{RMCH}(n=50)$ and AHCH $(n=20)$ (Table 1$)$ and subdivided according to the change in treatment strategy, Group A (1973-2000, $n=100)$ and Group B (1998-2011, $n=85$ ). The most common clinical presentations were visual problems, headaches and endocrine dysfunction.

Of the 64/115 (55\%) patients who presented with hydrocephalus, 42 (66\%) required CSF diversion procedures. Of the 185 patients, 13 (7\%) died at median 5.9 (0.3-15.4) years after initial surgery from recurrence and/or hypothalamic or neurological deficits (with/ without epilepsy and endocrinopathies).

\section{Initial treatment modality and trend in tumour recurrence over time}

More Group A than Group B patients underwent CR (34\% vs $19 \%, P=0.02$ ) and thus fewer required RT ( $28 \%$ vs $62 \%$, $P<0.001$ ) (Table 2). The proportion of patients who had limited or no surgery was greater in Group $B$ than that in Group A (35\% vs 16\%, $P=0.002)$.

The outcomes from the three surgical modalities with RT and without RT (i.e. surveillance) are summarised in Fig. 1 for our entire series and Fig. 2 for Groups A and B. The overall recurrence rate across the 4 decades was 35\% (65/185), and after CR, it was $24 \%$ (Table 2). Neither tumour recurrence rates in all patients ( $38 \%$ vs $32 \%, P=0.4$ ) nor in those who received RT ( $32 \%$ vs $26 \%, P=0.6$ ) differed significantly between Groups A and B (Table 2).

Table 2 Treatment modalities and tumour recurrence rates for Groups A (1973-2000) and B (1998-2011), as defined in Fig. 1 $(n=185)$. Data in this table is presented as number of patients $(\%)$. The extent of tumour resection was classified as complete resection (CR) or partial resection (PR) when it was total or subtotal removal respectively. Limited surgery (LS) includes procedures such as ventriculostomy, Ommaya reservoir and ventriculoperitoneal shunt with or without cyst aspiration. Incomplete surgery (IS) refers to PR and LS. Bolded text signify statistically significant $P$-values.

Tumour recurrence Complete resection (CR)

Recurrence after CR without radiotherapy (RT) Incomplete surgery (IS) and RT

Recurrence after IS and RT

Surveillance after any type of surgical approach Recurrence after surveillance

Adjuvant RT

Recurrence after RT

\begin{tabular}{c}
\hline Total (Group A and B) \\
\hline $65 / 185(35)$ \\
$50 / 185(27)$ \\
$11 / 45(24)$ \\
$76 / 185(41)$ \\
$22 / 76(29)$ \\
$104 / 185(56)$ \\
$42 / 104(40)$ \\
$81 / 185(44)$ \\
$23 / 81(28)$
\end{tabular}

\begin{tabular}{c}
\hline Group B $(n=85)$ \\
\hline $27 / 85(32)$ \\
$16 / 85(19)$ \\
$5 / 14(36)$ \\
$51 / 85(60)$ \\
$13 / 51(25)$ \\
$32 / 85(38)$ \\
$13 / 32(41)$ \\
$53 / 85(62)$ \\
$14 / 53(26)$ \\
\hline
\end{tabular}

\begin{tabular}{c}
\hline $\boldsymbol{P}(\chi 2, A$ vs $B)$ \\
\hline 0.4 \\
$\mathbf{0 . 0 2}$ \\
0.2 \\
$<\mathbf{0 . 0 0 1}$ \\
0.3 \\
$<\mathbf{0 . 0 0 1}$ \\
1.0 \\
$<\mathbf{0 . 0 0 1}$ \\
0.6 \\
\hline
\end{tabular}

www.eje-online.org 


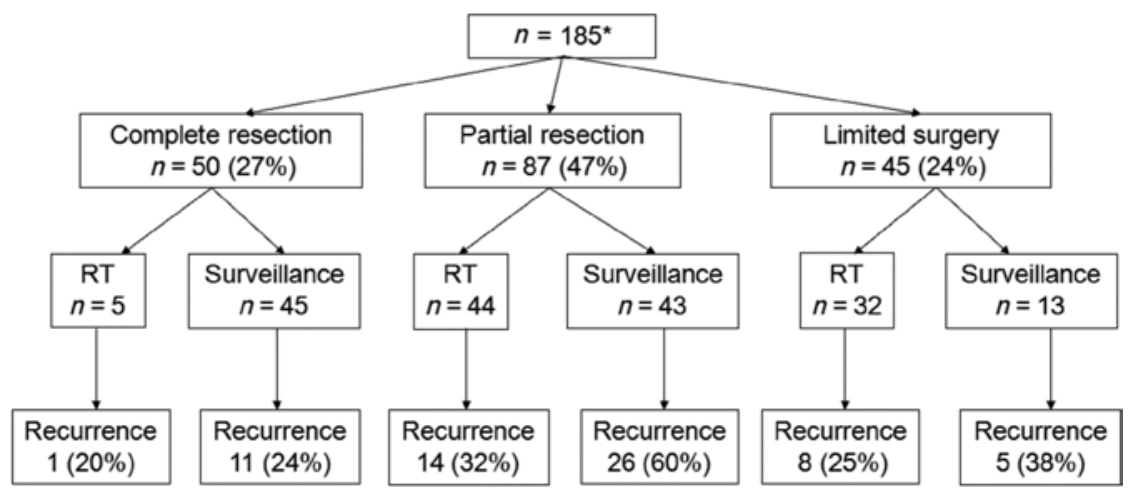

\section{Figure 1}

Extent of surgical resection, radiotherapy (RT) and recurrence for all patients across the 3 centres from 1973 to 2011 . Extent of tumour resection was classified as complete resection or partial resection when it was total or subtotal removal respectively. Limited surgery refers to procedures such as ventriculostomy, Ommaya reservoir and ventriculoperitoneal shunt with or without cyst aspiration. *Post-operative neuroimaging data for two patients were not available and the extent of surgery could not be ascertained. They underwent surveillance and had no recurrence. 1 patient underwent a watch-and-wait strategy without any radiotherapy. No tumour recurrence was reported for this patient.

\section{Anterior and posterior pituitary endocrinopathies}

Panhypopituitarism was defined as the deficiency of all anterior pituitary hormones with DI. Hormone deficiencies at diagnosis and at most recent follow-up for Groups A and B are presented in Table 3. However, data for individual pituitary hormones were not available at diagnosis for Group A. Post-operative panhypopituitarism $(P=0.001)$, gonadotrophin $(\mathrm{GTH})$ deficiency $(P<0.001)$ and DI $(P=0.04)$ were significantly lower in Group B than those in A despite similar follow-up times.

\section{Hypothalamic morbidity}

Hypothalamic morbidity rates did not differ significantly before and after surgery between Groups A and B postoperatively ( $P=0.2$ and 0.1 ) (Table 4$)$.

BMI SDS at diagnosis and at the last follow-up for Groups A and B is shown in Fig. 3 (data for GOSH Study 1 not available). Between Groups A and B, BMI SDS at last follow-up $(P=0.1)$ (Table 4$)$ and change in BMI SDS from presentation to last follow-up $(P=0.2)$ did not differ. There was also no significant difference between the two groups in the proportion of patients with a BMI SDS $>+2.0$ at presentation $(14 \%$ vs $26 \%, P=0.3)$ and at last follow-up ( $36 \%$ vs $46 \%, P=0.4$ ) (Table 4 ) and who experienced a BMI SDS increase of $\geq+1.0$ after surgery ( $38 \%$ vs $47 \%, P=0.5$ ). In contrast to Group A, in Group
B, there was a significant increase from presentation to last follow-up in the proportion of patients with hypothalamic symptoms $(49 \%$ vs $80 \%, \quad P=0.04)$ and with BMI $>+2$ SDS (26\% vs $46 \%, P=0.01$ ) (Fig. 3 and Table 4).

\section{Visual morbidity}

Data for visual morbidity was available for all patients in Group A but only for 36 patients in Group B. For all cohorts, there were no significant differences in visual morbidity before and after surgery (90/135 (67\%) vs $96 / 136$ (71\%), $P=0.5$ ). Similarly, no significant differences were noted before and after surgery in Groups A (60/100 (60\%) vs $68 / 100(68 \%), P=0.2)$ and B (30/35 (86\%) vs $28 / 36(78 \%), P=0.4)$. Post-operative visual morbidity rates between Groups A and B (68/100 (68\%) vs 28/36 (78\%), $P=0.3)$ did not differ significantly.

\section{Discussion}

\section{Management strategy, disease stabilisation and risk of tumour recurrence}

Our study comprises 185 children with craniopharyngioma managed at three tertiary centres from 1973 to 2011. Over these four decades, the management strategy shifted from a preference for radical surgery and avoiding RT in the earlier period (1973-2000) to more conservative surgery and 
A

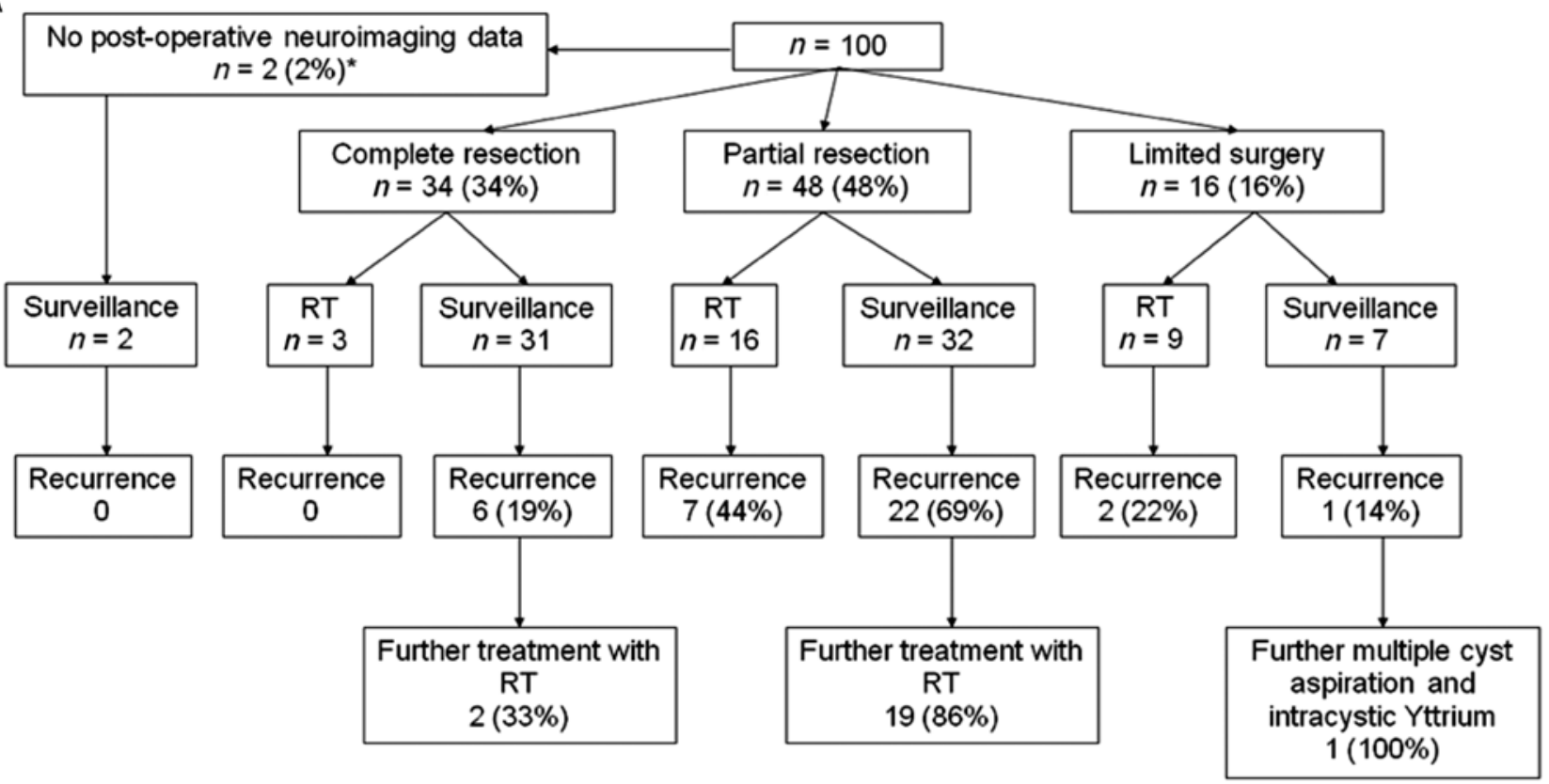

B

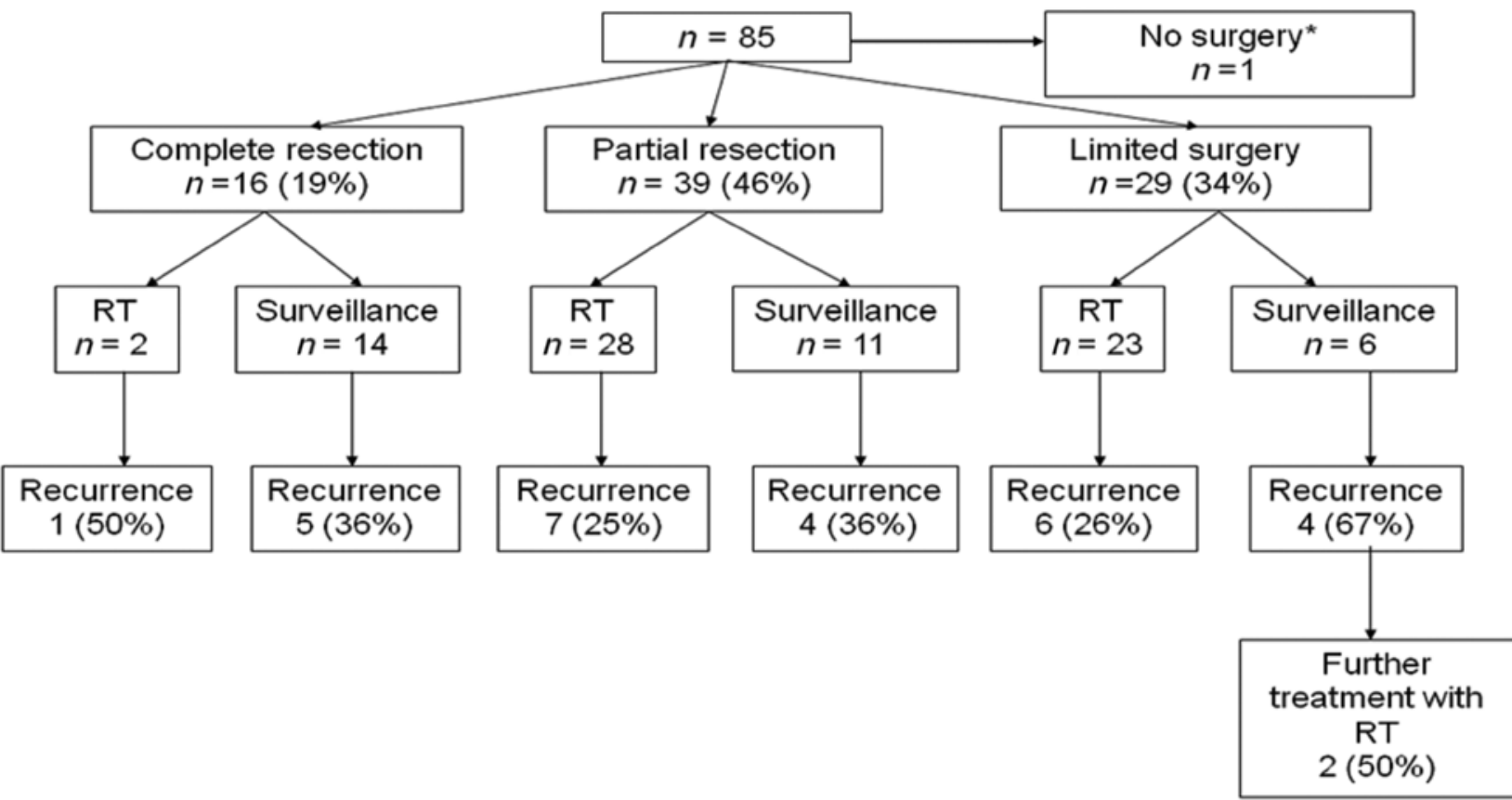

Figure 2

Extent of surgical resection, radiotherapy (RT) and recurrence for patients (A) Study Group A (1973-2000) and (B) Study Group B (1998-2011). (A) *Post-op neuroimaging data for two patients were not available and the extent of surgery could not be ascertained. They underwent surveillance and had no recurrence. (B) *1 patient underwent a watch-and-wait strategy without any radiotherapy. No tumour recurrence was reported for this patient.

adjuvant RT later on (1998-2011). This was associated with no major change in tumour recurrence (A: $38 \%$ to B: $32 \%$ ). In the absence of RT, tumour recurrence rates varied with the extent of surgery and time period and were highest after PR in Group A (69\%). Deaths have also decreased possibly owing to more intensive management of comorbidities. 
Table 3 Pituitary hormone deficiencies across the 3 centres for Groups A (1973-2000) and B (1998-2011). Data are presented as the number of patients with a hormone deficiency/number of patients tested (\%).

\begin{tabular}{|c|c|c|c|c|c|c|c|}
\hline & & TSH & АСTH & GH & Gonadotrophins $^{\dagger}$ & Diabetes insipidus & Panhypopituitarism \\
\hline \multirow[t]{2}{*}{ Group A $(n=100)$} & At diagnosis & NA & NA & NA & NA & NA & $50 / 100(50)$ \\
\hline & $\begin{array}{l}\text { Latest follow } \\
\text { up after } \\
\text { surgery } \pm R T^{\S}\end{array}$ & 70/75 (93) & $64 / 75$ (85) & $72 / 75(96)$ & $71 / 75$ (95) & $60 / 75(80)$ & $68 / 100(68)$ \\
\hline \multirow[t]{2}{*}{ Group B $(n=85)$} & At diagnosis & $\begin{array}{c}22 / 84(26) \\
1 \text { NA }\end{array}$ & $\begin{array}{c}21 / 84(25) \\
1 \mathrm{NA}\end{array}$ & $\begin{array}{c}26 / 64(41) \\
21 \text { NA }\end{array}$ & $15 / 75(20), 10 \mathrm{NA}$ & $6 / 85(7)$ & $21 / 44$ (48), $41 \mathrm{NA}$ \\
\hline & $\begin{array}{l}\text { Latest follow } \\
\text { up after } \\
\text { surgery } \pm R T\end{array}$ & $\begin{array}{c}\text { 70/81 (86) } \\
4 \text { NA }\end{array}$ & $\begin{array}{c}63 / 81 *(78) \\
4 \text { NA }\end{array}$ & $\begin{array}{c}\text { 75/81 (93), } \\
4 \text { NA }\end{array}$ & $\begin{array}{c}47 / 79 * *(59) \\
6 \text { NA }\end{array}$ & $55 / 84(65), 1 \mathrm{NA}$ & $35 / 81(43), 4 \mathrm{NA}$ \\
\hline$P \chi^{2}$ Group A vs B & & $P=0.2$ & $P=0.2$ & $P=0.4$ & $P<0.001$ & $P=0.04$ & $P=0.001$ \\
\hline
\end{tabular}

${ }^{\dagger}$ Gonadotrophin deficiency was defined based on biochemical findings of low LH and FSH levels on GnRH stimulation and patients requiring sex steroid replacement; ' data on individual pituitary axes not available for 25 patients; *1 patient did not have biochemical evidence of ACTH deficiency (hence not included) but had clinical features of glucocorticoid deficiency; ${ }^{* *} 1$ patient did not have biochemical evidence of gonadotrophin deficiency, but instead she experienced precocious puberty.

NA, data not available. Bolded text signify statistically significant $P$-values.

\section{Change in surgical management over time in our series compared to other major centres}

The most compelling trends in management are evident between 1975 and 2011 from Toronto Hospital for Sick Children (20) and between 1966 and 2012 from three large consecutive multinational studies undertaken by German researchers $(22,23)$. At the Hospital for Sick Children, the proportion of children who had CR in the periods 1975-1989 $(n=50), 1990-2001 \quad(n=43)$ and 2001-2011 $(n=33)$ was 90,86 and $12 \%$ respectively (20). In the three European nations' studies, $38 \%$ children had CR in the period 2001-2007 $(n=120)$ and only $18 \%$ in 2007-2012 $(n=106)(22,23)$. Before 2000, the transcranial approach was used more widely across our centres to achieve CR where radical tumour removal was the goal. Over time and since the 2005 UKMG, there has been greater use of the trans-sphenoidal approach and limited surgery especially for patients with poor risk factors, i.e. younger

Table 4 Hypothalamic dysfunction and BMI SDS for Groups A (1973-2000) and B (1998-2011).

Proportion (\%) of patients with
hypothalamic symptoms

Median (range) BMI SDS

Median (range) postoperative BMI SDS by surgical treatment Proportion (\%) of patients with BMI
$>2$ SDS*

At presentation
At last follow-up
$P$-value for within group difference
between presentation and last
follow-up

At presentation

At last follow-up

Change from presentation to post-op

Complete resection

Incomplete resection

At presentation

Post-op at last follow-up

$P$-value for within group difference

between presentation and last

follow-up

\begin{tabular}{|c|c|c|}
\hline Group A & Group B & $\boldsymbol{P}$ (Chi square) \\
\hline $62 / 100(62)$ & 19/39 (49), $46 \mathrm{NA}$ & 0.2 \\
\hline $\begin{array}{c}58 / 100(58) \\
0.6\end{array}$ & $\begin{array}{c}12 / 15(80), 70 \mathrm{NA} \\
\mathbf{0 . 0 4}\end{array}$ & 0.1 \\
\hline
\end{tabular}

$\begin{array}{lll}0.80(-2.00 ; 2.50) & 1.20(-2.92 ; 4.52) & 0.8 \\ 1.33(-2.15 ; 4.30) & 1.94(-0.71 ; 4.50) & 0.1 \\ 0.80(-2.70 ; 3.25) & 0.88(-2.54 ; 5.31) & 0.2\end{array}$

$\begin{array}{lc}\text { NA } & 2.52(0.23 ; 3.92) \\ \text { NA } & 2.00(-0.71 ; 4.50)\end{array}$

$\begin{array}{ccc}3 / 21(14) & 19 / 73(26) & 0.3 \\ 8 / 22(36) & 32 / 69(46) & 0.4 \\ 0.1 & \mathbf{0 . 0 1} & \end{array}$

At presentation Post-op at last follow-up

\begin{tabular}{lll}
$2.40(2.30 ; 2.50)$ & $2.45(2.02 ; 4.52)$ & 0.9 \\
$2.93(2.15 ; 4.30)$ & $2.91(2.07 ; 4.50)$ & 0.9 \\
\hline
\end{tabular}

Median (range) BMI SDS for all obese
patients

Obesity, BMI > 2 SDS; severe obesity, BMI >4 SDS (20). Bolded text signify statistically significant $P$-values.

*No. of patients with BMI $>4$ SDS were at presentation 0 and 1/73 (1\%) patient in Groups A and B respectively, Post-op at last follow-up 1/22 (5\%) and $2 / 69$ (3\%) patients in Groups A and B respectively.

NA, data not available. 


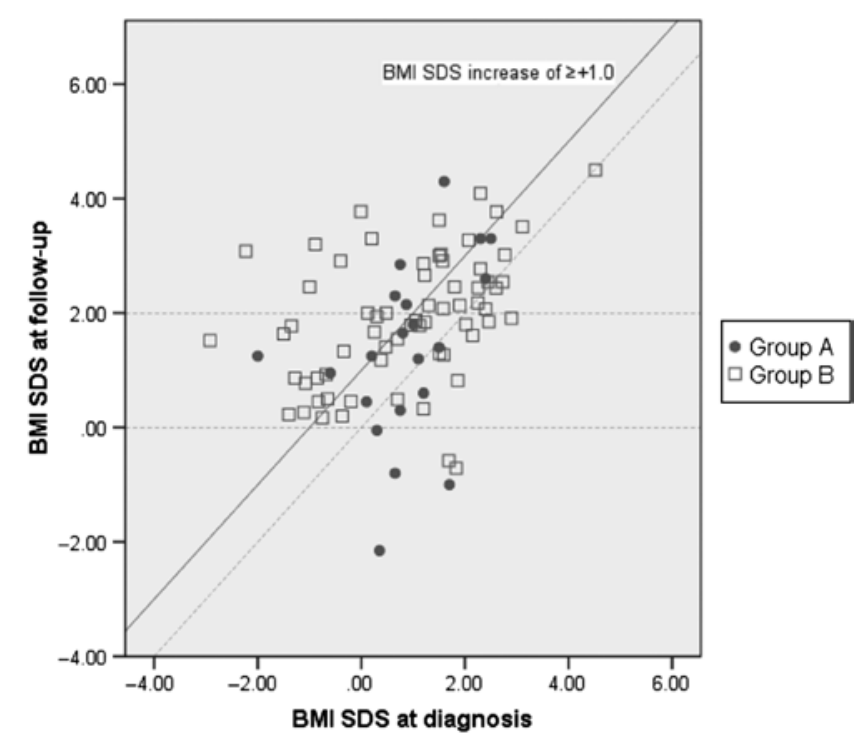

Figure 3

BMI SDS at diagnosis and at last follow-up for Groups A (1973-2000) and B (1998-2011). *Solid diagonal line denotes BMI SDS increase of $\geq+1.0$ from diagnosis to follow-up.

children aged $<5$ year with large tumours $>2-4 \mathrm{~cm}$ and hypothalamic syndrome or hydrocephalus at diagnosis (16). Thus, the general decline in the rates of CR in our experience is in keeping with the UKMG and other studies $(16,24)$.

\section{Recurrence rates in our series compared to other published studies}

Numerous publications have reported experiences, outcomes and risk-benefit profiles of primary management modalities for craniopharyngioma in children and adolescents. Among these are the multinational studies mentioned previously $(20,22,21,22,23)$. Other publications are observational reports from single centres with relatively small numbers of paediatric patients and some also include adult patients owing to the rarity of the condition. In the absence of randomised trials and metaanalysis, these studies do provide valuable insight which has been summarised in a number of reviews $(1,9,14,25$, $26,27,28)$.

The $24 \%$ rate of recurrence in our study after CR across 4 decades compares favourably to the 35\% reported by Clarke et al. in a systematic review of 109 publications from 1977 to 2012 with data on recurrence available for 377 of 531 paediatric patients (25). For partially resected tumours treated with RT, the recurrence risk of 50\% was considerably higher than the $32 \%$ in our patients. However, the number of patients in each study included in this review was small (median 11, range 1-29). Mortini et al. (1) reviewed 26 studies published between 1990 and 2012. These studies were not restricted to the paediatric population, and recurrence rates varied widely: up to 50\% after CR and 25-100\% after PR.

\section{Endocrinopathies}

The missing information about individual pituitary hormone status at diagnosis for Group A precludes comparing whether there was a change from diagnosis to last follow-up in Group A and also individual hormone deficiencies at diagnosis between the two groups. However, we would not anticipate the latter to be significantly different, and this is further supported by the proportion of patients with panhypopituitarism being similar (Group A 50\% vs Group B 48\%). At the latest follow-up, from the earlier Group A (1973-2000) to the more recent Group B study (1998-2011), we found a significant reduction in the occurrence of DI (80-65\%), GTH deficiency (95-59\%) and panhypopituitarism (68-43\%). The move towards a more conservative approach with adjuvant RT as well as the increased use of the trans-sphenoidal route was likely to have contributed to preserving the pituitary stalk and the hypothalamic-pituitary integrity. This has benefits for survival and reproductive capacity. Cohen et al. (20) from Toronto observed similar trends from 1975 to 2011 for DI (93-55\%) and panhypopituitarism (86-58\%). Although they reported an increased frequency of GH (20-85\%) and GTH deficiency (30-61\%) across their cohorts, the prevalence of these endocrinopathies in their most recent cohort was similar to our Group B (93\% GH and 59\% GTH deficiency). Better diagnostic awareness over the years may explain these findings.

\section{Hypothalamic morbidity}

Affective behaviour and memory were not evaluated with standardised assessments for all patients routinely across all the centres. Thus, our findings for hypothalamic morbidity are limited to clinical manifestations and BMI data. Hypothalamic morbidity remained prevalent at diagnosis and post-operatively with $58 \%$ and $61 \%$ patients respectively affected across our 6 cohorts from 1973 to 2011. The lack of differences in rates of post-operative hypothalamic dysfunction and obesity between the two time periods suggests that hypothalamic morbidity continues to be a challenging burden. Moreover, despite a greater preference for hypothalamic sparing strategies in Group B, post-operative hypothalamic morbidity worsened 
significantly from diagnosis. Thus, as previously reported by Müller et al. (29), obesity appears to be inherent to the disease itself rather than the treatment imposed. Despite a similar BMI change from diagnosis to the post-operative period between Groups A and B (median BMI SDS 0.80 vs 0.88 ), there was a higher prevalence of obesity at baseline in Group B (A: $14 \%$ vs B: $26 \%$, median BMI SDS - A: 0.80 vs $B: 1.20)$. This may reflect more recent secular trends of higher rates of obesity (boys and girls of age $<20$ years: $4.7-7.4 \%$ and $5.7-8.1 \%$ from 1980 to 2013 respectively) seen in the paediatric population in the United Kingdom over the last 4 decades (30). The significant increase in rates of hypothalamic morbidity from presentation to last follow-up in Group B but not in Group A might be explained by greater awareness and documentation of this complication in recent times.

Müller and coworkers have highlighted the prevalence, prognostic indicators and sequelae of hypothalamic involvement from their landmark studies (31). This includes long-term results from the largest cohort of survivors from the multi-centre HIT-Endo registry (32). Progression-free survival at 20 years was $58 \%$ and was not influenced by hypothalamic involvement or extent of resection. Those with hypothalamic involvement (compared to those without) had lower overall survival at 20 years ( $84 \%$ vs $95 \%$ ) and impaired quality of life from obesity, physical fatigue, dyspnoea, lack of motivation and impaired psychosocial development.

\section{Visual morbidity}

The lack of any significant differences in visual morbidity pre- and post-operatively ( $67 \%$ vs $71 \%$ ) and between the two study periods (68\% vs $78 \%$ ) demonstrates that this remains another major burden of craniopharyngioma. It is well established that over $50 \%$ of children with these tumours will have a myriad of visual field and acuity deficits at diagnosis and at follow-up $(25,33)$. Although surgical decompression has an important role in preserving vision, operative trauma to the visual apparatus can worsen visual field defects (19). RT given in close proximity to the optic nerves also increases the risk of visual impairment (34).

\section{Tailored management based on evaluating individual risk and prognostic factors}

Our practice enshrined in the UKMG is in keeping with a worldwide shift towards a more tailored approach and preference for conservative surgery along with RT for long-term disease control $(14,35)$. The emphasis is also to minimise morbidity rather than ambitious attempts to completely excise this heterogeneous tumour. Although the complications from pituitary damage can be managed relatively easily with hormone replacement, the risk of premature mortality and loss of reproductive function cannot be eliminated. Additionally, no effective treatment is available for the debilitating morbidity arising from injury to the hypothalamus (31) and visual apparatus. There is thus an increased focus on identifying individual risk and tailoring treatment accordingly. To enable risk stratification, a variety of classifications have been proposed based on the patient's age, clinical cues for morbidity, tumour size, location, extension and relationship with vital structures and markers of hypothalamic involvement on MRI such as involvement of third ventricle, mammillary body and obstructive hydrocephalus $(1,15,36,37,38,39)$. Based on their findings of lower progression-free survival in those with tumours $\geq 4.5 \mathrm{~cm}$, Yosef et al. (40) have also appealed for a worldwide consensus on classification by size of tumour.

\section{Radiotherapy in the primary treatment of craniopharyngioma}

The rationale for RT in the primary treatment of craniopharyngioma is to stabilise residual disease after PR and avoid the unfavourable morbidity and mortality after CR (41). Our findings are in agreement with observations that the combination of conservative surgery and RT achieves tumour control that is similar to $\mathrm{CR}$ alone $(29,31,32)$.

\section{Strengths and limitations of the study}

In this study, we have the advantage of evaluating tumour control and associated sequelae in a large cohort of patients managed with a range of surgical strategies, with or without adjuvant RT and with data that spans four decades. All were managed at large tertiary centres recognised to have the relevant paediatric neuro-oncology, neuroendocrinology and neurosurgical expertise.

A major limitation was that meta-data available from the six independent studies were analysed retrospectively and missing information could not be obtained. The follow-up duration for individual studies may not be sufficiently long to fully ascertain the outcomes of treatment on morbidity and survival rates. When 
examining the impact of various surgical modalities on tumour recurrences, we were not able to control for confounding variables such as the age of the patient, duration of history before diagnosis (42), modern surgical technology and neuroimaging. Selection bias in the choice of treatment especially in patients with particular baseline clinical characteristics is a limitation beyond our control. Data on other pertinent outcomes, such as quality of life (33) and neurocognitive function (43), were not available.

\section{Conclusion}

Although subject to the limitations of incomplete metadata, our results offer a clear timeline message that limited surgery/subtotal resection combined with adjuvant RT achieved similar rates of tumour control as planned CR. Importantly, the minimal radical surgical approaches employed and the greater use of adjuvant RT over time were associated with reduced endocrine morbidity. However, reducing the burden of hypothalamic and visual morbidity remains a challenge and more effective targeted therapies are necessary to improve outcomes.

\section{Declaration of interest}

The authors declare that there is no conflict of interest that could be perceived as prejudicing the impartiality of the research reported.

\section{Funding}

This research did not receive any specific grant from any funding agency in the public, commercial or not-for-profit sector.

\section{Author contribution statement}

J S G, S E, M S, E C I, H S, M D, J B and B P provided details about the original studies from the respective centres. T S E T collected the metadata, analysed it and prepared the paper under supervision of $L P$ and P E C. R H, K A, C M and I K managed patients surgically and provided input on neurosurgical practices at the three respective centres. N T, M N G and $B$ P provided input on radiotherapy practice for treatment of paediatric craniopharyngioma in UK centres. All authors contributed to finalising the paper.

\section{Acknowledgements}

The authors thank Catherine De Vile, David B Grant, Brian E Kendall, Brian G R Neville, Richard Stanhope, Kate E Watkins from GOSH, Connor Mallucci, Arun Doss, Swathi Upadrasta, William Newman, Shivaram Avula and Benedetta Petterini from $\mathrm{AHCH}$ for their contribution towards conducting and disseminating results of the craniopharyngioma audits/ studies at their respective centres.

\section{References}

1 Mortini P, Gagliardi F, Boari N \& Losa M. Surgical strategies and modern therapeutic options in the treatment of craniopharyngiomas.
Critical Reviews in Oncology/Hematology 201388 514-529. (doi:10.1016/j.critrevonc.2013.07.013)

2 Lannalfi A, Fragkandrea I, Brock J \& Saran F. Radiotherapy in craniopharyngiomas. Clinical Oncology (Royal College of Radiologists) 201325 654-667. (doi:10.1016/j.clon.2013.07.005)

3 Bunin GR, Surawicz TS, Witman PA, Preston-Martin S, Davis F \& Bruner JM. The descriptive epidemiology of craniopharyngioma. Journal of Neurosurgery 199889 547-551. (doi:10.3171/jns.1998.89.4.0547)

4 Elowe-Gruau E, Beltrand J, Brauner R, Pinto G, Samara-Boustani D, Thalassinos C, Busiah K, Laborde K, Boddaert N, Zerah M et al. Childhood craniopharyngioma: hypothalamus-sparing surgery decreases risk of obesity. Journal of Clinical Endocrinology and Metabolism 201398 2376-2382. (doi:10.1210/jc.2012-3928)

5 Clark AJ, Cage TA, Aranda D, Parsa AT, Sun PP, Auguste KI \& Gupta N. A systematic review of the results of surgery and radiotherapy on tumor control for pediatric craniopharyngioma. Child's Nervous System 201329 231-238. (doi:10.1007/s00381-012-1926-2)

6 Merchant TE, Kun LE, Hua CH, Wu S, Xiong X, Sanford RA $\&$ Boop FA. Disease control after reduced volume conformal and intensity modulated radiation therapy for childhood craniopharyngioma. International Journal of Radiation Oncology, Biology, Physics 201385 e187-e192. (doi:10.1016/j.ijrobp.2012.10.030)

7 Schoenfeld A, Pekmezci M, Barnes MJ, Tihan T, Gupta N, Lamborn KR, Banerjee A, Mueller S, Chang S, Berger MS et al. The superiority of conservative resection and adjuvant radiation for craniopharyngiomas. Journal of Neuro-Oncology 2012108 133-139. (doi:10.1007/s11060-012-0806-7)

8 Winkfield KM, Tsai HK, Yao X, Larson E, Neuberg D, Pomeroy SL, Ullrich NJ, Cohen LE, Kieran MW, Scott RM et al. Long-term clinical outcomes following treatment of childhood craniopharyngioma. Pediatric Blood and Cancer 201156 1120-1126. (doi:10.1002/ pbc.22884)

9 Yang I, Sughrue ME, Rutkowski MJ, Kaur R, Ivan ME, Aranda D, Barani IJ \& Parsa AT. Craniopharyngioma: a comparison of tumor control with various treatment strategies. Neurosurgical Focus 201028 E5. (doi:10.3171/2010.1.FOCUS09307)

10 Yang I, Sughrue ME, Rutkowski BA, Kaur R, Ivan ME, Aranda D, Barani IJ \& Parsa AT. Craniopharyngioma: a comparison of tumour control with various treatment strategies. Neurosurgical Focus 201028 E5. (doi:10.3171/2010.1.FOCUS09307)

11 Müller HL, Gebhardt U, Teske C, Faldum A, Zwiener I, WarmuthMetz M, Pietsch T, Pohl F, Sorensen N, Calaminus G et al. Post-operative hypothalamic lesions and obesity in childhood craniopharyngioma: results of the multinational prospective trial KRANIOPHARYNGEOM 2000 after 3-year follow-up. European Journal of Endocrinology 2011165 17-24. (doi:10.1530/EJE-11-0158)

12 Clark AJ, Cage TA, Aranda D, Parsa AT, Auguste KI \& Gupta N. Treatment-related morbidity and the management of pediatric craniopharyngioma: a systematic review. Journal of Neurosurgery: Pediatrics 201210 293-301. (doi:10.3171/2012.7.PEDS11436)

13 Lin LL, El Naqa I, Leonard JR, Park TS, Hollander AS, Michalski JM \& Mansur DB. Long-term outcome in children treated for craniopharyngioma with and without radiotherapy. Journal of Neurosurgery: Pediatrics 20081 126-130. (doi:10.3171/PED/2008/1/2/126)

14 Puget S. Treatment strategies in childhood craniopharyngioma. Frontiers in Endocrinology 20123 64. (doi:10.3389/fendo.2012.00064)

15 Müller HL. Preoperative staging in childhood craniopharyngioma: standardization as a first step towards improved outcome. Endocrine 201651 1-3. (doi:10.1007/s12020-015-0800-x)

16 Spoudeas HA. Craniopharyngioma. In Paediatric Endocrine Tumours. A Multi-Disciplinary Consensus Statement of Best Practice from A Working Group Convened under the Auspices of the BSPED and UKCCSG (Rare Tumour Working Groups), edn. 1, ch. 1, pp 16-46. Crawley, UK: Novo Nordisk Ltd, 2005.

17 Morillon P, Perelberg D, Losa L, Ederies A, Aquilina K, Doward N, Michalski A, Hargrave D, Chang YC, Bozorgi N et al. Three year 
experience of a national interdisciplinary initiative to improve outcomes for children with hypothalamic pituitary axis tumours (HPATs) using multi-site videoconferencing for decision making on Behalf of the UK HPAT Interest Group. Endocrine Abstracts 201436 P78. (doi:10.1530/endoabs.36.P78)

18 De Vile CJ, Grant DB, Kendall BE, Neville BG, Stanhope R, Watkins KE \& Hayward RD. Management of childhood craniopharyngioma: can the morbidity of radical surgery be predicted? Journal of Neurosurgery 199685 73-81. (doi:10.3171/jns.1996.85.1.0073)

19 Mallucci C, Pizer B, Blair J, Didi M, Doss A, Upadrasta S, Newman W, Avula S \& Pettorini B. Management of craniopharyngioma: the Liverpool experience following the introduction of the CCLG guidelines. Introducing a new risk assessment grading system. Child's Nervous System $2012 \mathbf{2 8}$

1181-1192. (doi:10.1007/s00381-012-1787-8)

20 Cohen M, Bartels U, Branson H, Kulkarni AV \& Hamilton J. Trends in treatment and outcomes of pediatric craniopharyngioma, 1975-2011. Neuro-Oncology 201315 767-774. (doi:10.1093/neuonc/not026)

21 Cole TJ, Freeman JV \& Preece MA. Body mass index reference curves for the UK, 1990. Archives of Disease in Childhood 199573 25-29. (doi:10.1136/adc.73.1.25)

22 Müller HL, Gebhardt U, Etavard-Gorris N, Korenke E, WarmuthMetz M, Kolb R, Sörensen N \& Calaminus G. Prognosis and sequelae in patients with childhood craniopharyngioma - results of HIT-ENDO and update on KRANIOPHARYNGEOM 2000. Klinische Pädiatrie 2004 216 343-348. (doi:10.1055/s-2004-832339)

23 Hoffmann A, Warmth-Metz M, Gebhardt U, Pietsch T, Pohl F, Kortmann RD, Calaminus G \& Müller HL. Childhood craniopharyngioma - changes of treatment strategies in the trials KRANIOPHARYNGEOM 2000/2007. Klinische Pädiatrie 2014226 161-168. (doi:10.1055/s-0034-1368785)

24 Thomas D, Phipps K \& Hayward R. Craniopharyngioma in childhood: our evidence-based approach to management. Child's Nervous System 200521 660-668. (doi:10.1007/s00381-005-1210-9)

25 Clark AJ, Cage TA, Aranda D, Parsa AT, Sun PP, Auguste KI \& Gupta N. A systematic review of the results of surgery and radiotherapy on tumor control for pediatric craniopharyngioma. Child's Nervous System 201329 231-238. (doi:10.1007/s00381-012-1926-2)

26 Müller HL. Craniopharyngioma. Endocrine Reviews 201435 513-543. (doi:10.1210/er.2013-1115)

27 Müller HL. Consequences of craniopharyngioma surgery in children. Journal of Clinical Endocrinology and Metabolism 201196 1981-1991. (doi:10.1210/jc.2011-0174)

28 Sughrue ME, Yang I, Kane AJ, Fang S, Clark AJ, Aranda D, Barani IJ $\&$ Parsa AT. Endocrinologic, neurologic, and visual morbidity after treatment for craniopharyngioma. Journal of Neuro-Oncology 2011101 463-476. (doi:10.1007/s11060-010-0265-y)

29 Müller HL, Emser A, Faldum A, Bruhnken G, Etavard-Gorris N, Gebhardt U, Oeverink R, Kolb R \& Sörensen N. Longitudinal study on growth and body mass index before and after diagnosis of childhood craniopharyngioma. Journal of Clinical Endocrinology and Metabolism 200489 3298-3305. (doi:10.1210/jc.2003-031751)

30 Ng M, Fleming T, Robinson M, Thomson B, Graetz N, Margono C, Mullany EC, Biryukov S, Abbafati C, Abera SF et al. Global, regional, and national prevalence of overweight and obesity in children and adults during 1980-2013: a systematic analysis for the Global Burden of Disease Study 2013. Lancet 2014384 766-781. (doi:10.1016/S01406736(14)60460-8)

31 Müller HL. Craniopharyngioma and hypothalamic injury: latest insights into consequent eating disorders and obesity. Current Opinion in Endocrinology, Diabetes and Obesity 201623 81-89. (doi:10.1097/ MED.0000000000000214)

32 Sterkenburg AS, Hoffmann A, Gebhardt U, Warmuth-Metz M, Daubenbüchel AM \& Müller HL. Survival, hypothalamic obesity, and neuropsychological/psychosocial status after childhood-onset craniopharyngioma: newly reported long-term outcomes. NeuroOncology 201517 1029-1038. (doi:10.1093/neuonc/nov044)

33 Yano S, Kudo M, Hide T, Shinojima N, Makino K, Nakamura H \& Kuratsu J. Quality of life and clinical features of long-term survivors surgically treated for pediatric craniopharyngioma. World Neurosurgery 201685 153-162. (doi:10.1016/j.wneu.2015.08.059)

34 Kiehna EN \& Merchant TE. Radiation therapy for pediatric craniopharyngioma. Neurosurgical Focus 201028 E10. (doi:10.3171/20 10.1.FOCUS09297)

35 Müller HL. Risk-adapted treatment and follow-up management in childhood-onset craniopharyngioma. Expert Review of Neurotherapeutics 201616 535-548. (doi:10.1586/14737175.2016.116 6959)

36 Mortini P, Gagliardi F, Bailo M, Spina A, Parlangeli A, Falini A \& Losa M. Magnetic resonance imaging as predictor of functional outcome in craniopharyngiomas. Endocrine 201651 148-162. (doi:10.1007/s12020-015-0683-x)

37 Müller HL, Gebhardt U, Teske C, Faldum A, Zwiener I, WarmuthMetz M, Pietsch T, Pohl F, Sörensen N, Calaminus G et al. 2000. Post-operative hypothalamic lesions and obesity in childhood craniopharyngioma: results of the multinational prospective trial KRANIOPHARYNGEOM 2000 after 3-year follow-up. European Journal of Endocrinology 2011165 17-24. (doi:10.1530/EJE-11-0158)

38 Pan J, Qi S, Liu Y, Lu Y, Peng J, Zhang X, Xu Y, Huang GL \& Fan J. Growth patterns of craniopharyngiomas: clinical analysis of 226 patients. Journal of Neurosurgery: Pediatrics 201617 418-433. (doi:10.3 171/2015.7.PEDS14449)

39 Puget S, Garnett M, Wray A, Grill J, Habrand JL, Bodaert N, Zerah M, Bezerra M, Renier D, Pierre-Kahn A et al. Pediatric craniopharyngiomas: classification and treatment according to the degree of hypothalamic involvement. Journal of Neurosurgery 2007 106 3-12. (doi:10.3171/ped.2007.106.1.3)

40 Yosef L, Ekkehard KM \& Shalom M. Giant craniopharyngiomas in children: short- and long-term implications. Child's Nervous System 201632 79-88. (doi:10.1007/s00381-015-2961-6)

41 Aggarwal A, Fersht N \& Brada M. Radiotherapy for craniopharyngioma. Pituitary 201316 26-33. (doi:10.1007/s11102012-0429-1)

42 Hoffmann A, Boekhoff S, Gebhardt U, Sterkenburg AS, Daubenbüchel AM, Eveslage M \& Müller HL. History before diagnosis in childhood craniopharyngioma: associations with initial presentation and long-term prognosis. European Journal of Endocrinology 2015173 853-862. (doi:10.1530/EJE-15-0709)

43 Özyurt J, Müller HL \& Thiel CM. A systematic review of cognitive performance in patients with childhood craniopharyngioma. Journal of Neuro-Oncology 2015125 9-21. (doi:10.1007/s11060-015$1885-\mathrm{z})$

Received 27 September 2016

Revised version received 1 December 2016

Accepted 10 January 2017 